\title{
Aesthetic, Ethical, and Cognitive Value ${ }^{1}$
}

\author{
Cain Todd \\ Department of Philosophy, \\ Lancaster University, \\ Lancaster \\ LA1 4YG, U.K. \\ c.todd@lancaster.ac.uk
}

\begin{abstract}
This paper addresses two recent debates in aesthetics: the 'moralist debate', concerning the relationship between the ethical and aesthetic evaluations of artworks, and the 'cognitivist debate', concerning the relationship between the cognitive and aesthetic evaluations of artworks. Although the two debates appear to concern quite different issues, I argue that the various positions in each are marked by the same types of confusions and ambiguities. In particular, they demonstrate a persistent and unjustified conflation of aesthetic and artistic value, which in turn is based on a more general failure to explicitly tackle the demarcation of aesthetic value. As such, the claims of each side are rendered ambiguous in respect of the relation that is supposed to hold between all these types of value and artistic value. These issues are discussed in light of a recent argument proposed by Matthew Kieran, to undermine, to some extent, the conceptual distinction between aesthetic, cognitive-ethical, and artistic values in our appraisal of art works. In rejecting his argument, I defend the conceptual distinction and a pluralistic conception of artistic value that allows for cognitive and ethical values to count as artistic, but not aesthetic, values.
\end{abstract}

\section{The Moralist Debate}

A favourite, recurring example in contemporary philosophical discussion about the relation between the ethical and aesthetic evaluation of works of art is Leni Riefenstahl's film Triumph of the Will. This is held by some, autonomists, to be a paradigmatic case of how a negative ethical evaluation of the work's deplorable propagandistic message nevertheless does not detract from, or indeed has no impact on, its artistic or aesthetic merit. By opponents of autonomism it is taken, on the contrary, to be a clear case in

1 (C) 2007 Cain Todd; licensee South African Journal of Philosophy.

This is an open access article distributed under the terms of the Creative Commons Attribution License (http://creativecommons.org/licenses/by/2.5), which permits unrestricted use, distribution, and reproduction in any medium, provided the original work is properly cited.

I would like to thank Alix Cohen, and audiences at the University of Leeds and the PSSA conference at the University of Stellenbosch for their feedback and advice, which has helped me greatly in preparing this paper. 
which whatever aesthetic merit it possesses is mitigated or compromised by its moral flaws, namely the craven adoration of Hitler and Nazism.

In short, everyone agrees that art's moral content can be the legitimate subject of critical evaluation, but everyone differs over whether the ethical defects/merits of art can also be aesthetic defects/merits. Moderate Autonomism, the position outlined by Anderson and Dean, holds that they never are. In their outline and defence of MA, Anderson and Dean hold that:

the moral content of a work can contribute to or detract from the aesthetic aspects of a work. What distinguishes our view from the views of Carroll and Gaut, however, is our claim that it is never the moral component of the criticism as such that diminishes or strengthens the value of an artwork qua artwork. In short, both sorts of criticism are appropriate to works of art but the categories of moral and aesthetic criticism always remain conceptually distinct. (Anderson and Dean 1998: 152)

Thus, MA apparently allows some sort of interaction between ethical and aesthetic criticism, suggesting that a work's moral defects might affect its aesthetic or artistic value, where, for instance, they affect a work's structure, its coherence or complexity, and yet the two types of value will remain 'conceptually distinct'. So it seems possible that a work's moral defects could impair its aesthetic value, where this does not entail that the relevant ethical flaws in the work are as such aesthetic flaws. Note that the clarity and plausibility of the position hinges on i) what is included under the compass of 'aesthetic value'; ii) the precise nature of the interaction between ethical and aesthetic values; and iii) the relationship between aesthetic and artistic value.

These issues remain largely unexamined in their paper, which focuses instead on providing three plausible reasons for maintaining their position and then shifting the initial burden of proof for holding that moral defects/merits can be aesthetic defects/merits onto the opposing positions, developed by Gaut and Carroll, which, they argue persuasively, fail to meet the challenge. Anderson and Dean argue that:

i) There is a prima facie conceptual difference between aesthetic and ethical value

ii) Moderate autonomism best accounts for the prima facie tension we feel between aesthetic and ethical value when confronted with certain works.

iii) There are cases where a work's ethical flaw(s) can give rise to an aesthetic virtue if, for instance, it enhances the work's power or skill. That is, a work can be an aesthetic success in virtue of its skilful evocation and endorsement of, say, an evil perspective.

It seems to me that these arguments, if they are arguments, have a lot of intuitive appeal, for it does seem obvious that aesthetical and ethical value must be distinct in these ways. After all, our ethical and aesthetic appraisals often seem either to conflict directly with each other, or simply not to impinge upon nor overlap with each other in any way at all. Whilst engaging with works such as Pulp Fiction, Lolita, or de Sade's Juliette, we may feel to some extent repelled by the moral views represented and, more importantly, by the disturbing moral evaluations that the works seem to prescribe. Yet at the same time, we nevertheless revel in the artistic skill and aesthetic pleasure with which, in each case, the lavish and abhorrent violence, paedophilic desires, or intense sexual torture, are portrayed. And we might feel troubled by these mixed feelings of (aesthetic) delight and (moral) disgust. 
Indeed, it seems at least in the first two cases that the exploration of the relationship and perhaps tension between two different types of value lies at the heart of the intention and value of each piece (Ibid.: 165). More strongly, we might even think that the works are aesthetically enriched for being able to portray abhorrent and alien moral perspectives in such a way that they become absorbing and perhaps even, in some cases and to some extent, compelling. ${ }^{2}$

The 'ethicist' position developed by Berys Gaut (1998) attempts to meet the moderate autonomist challenge by arguing that certain types of ethical defect are always also aesthetic defects. Gaut holds that, if a work manifests immoral attitudes, we have a reason not to respond in the way prescribed. This represents a failure of the work qua work of art. What responses the work prescribes is of aesthetic relevance. Hence, insofar as a work manifests ethically bad (good) attitudes - an ethical defect - to this extent, the work will be aesthetically flawed.

Why should we accept that all unmerited prescriptions amount to aesthetic flaws? Because, Gaut argues:

The notion of the aesthetic adopted here should be construed broadly... I mean by "aesthetic value" the value of an object qua work of art, that is, its artistic value (Gaut 1998: 183).

In other words, Gaut claims that any defect of a work of art qua work of art is an aesthetic defect. Once aesthetic value is construed so broadly as to be made equivalent to artistic value, and moral value is held to be uncontroversially an important value of art, as MA itself appears to allow, then of course it is very easy to demonstrate that the relevant ethical flaws will also be aesthetic, i.e. artistic, flaws. But, as others have noted, as Gaut provides no independent argument for his purely stipulative definition, which conflates aesthetic and artistic value, his position clearly rests on an equivocation: by 'unmerited response', the ethicist means both ethically and aesthetically unmerited, and hence from a premise about ethical merit, he argues to a conclusion about aesthetic merit. ${ }^{3}$

For this reason alone, the autonomist ought to reject such a broad construal of 'aesthetic', but it is striking that, in the position statement quoted earlier, the autonomist too appears to hold that the value of art qua art is somehow equivalent to aesthetic value, since both are distinguished from the "moral component of the criticism as such.' So if the autonomist is to allow the appropriateness of moral criticism to works of art, the position must be that moral defects qua moral are relevant to the criticism and evaluation of art, but irrelevant to the value of art qua art.

On the one hand, it is difficult to make much sense of this position independently of an account of what the value of art qua art consists in. On the other hand, if we accept with the autonomist, as I contend we should, that there is a prima facie conceptual distinction between aesthetic and ethical value, then the autonomist position appears to be undermined by this conflation of artistic and aesthetic value. In any case, the danger of such a conflation is itself worth avoiding for independent reasons. One such reason is the worry that, if all values of art qua art were just aesthetic values, if that's what we meant by talking of the 'value of art qua art', we would struggle to make proper sense

2 For discussion see Kieran (2002).

3 For further criticisms of Ethicism, see Carroll (2000: 376) and Kieran (2001: $30 \mathrm{ff}$.). It is worth noting that Gaut himself confronts this objection head-on (197). However, as Anderson and Dean show (160), his counter-arguments are unsuccessful. 
of standard forms of critical evaluation, such as contrasting a work's formal or aesthetic virtues with, for example, its moral or cognitive content in our overall appraisal of an artwork's artistic value. We would be helpless to describe the different contributions to such value, made on the one hand, by a work's aesthetic flaws/merits, and on the other hand, by other non-aesthetic flaws/merits, such as moral or cognitive content.

If there is no good reason for denying the status of artistic value to these, the natural result of such considerations should be a pluralist position about artistic value, according to which ethical defects may be counted as failures of artworks qua artworks, in the sense that art can be evaluated morally. But this demonstrates merely that art has a range of values other than aesthetic. For example, Triumph of the Will might be deemed an overall artistic success, in virtue of its aesthetic virtues, but flawed as a work of art to the extent that it prescribes an objectionable moral outlook.

This value pluralism is thus the position that the autonomist ought to hold vis-à-vis the value of art qua art and its distinction from aesthetic value. More importantly, this distinction itself can be defended not merely by an appeal to the concerns for maintaining the value pluralism just expressed, but also for the rather obvious reason that, if nature and other non-art objects can be appreciated aesthetically, then clearly aesthetic value must be distinguishable from artistic value. To think otherwise betrays either a simple confusion or some theoretically laden views about the nature of aesthetic and artistic value, views which remain at best implicit in this debate, and at worst merely stipulated for the sake of argument.

It is notable that what has appeared to proponents to be a debate about the overlap between ethical and aesthetic value is in large part really a debate about the relationship between artistic and aesthetic value. There thus seems to be no reason why the autonomist cannot accept that some ethical values will not only be relevant to artistic value, but will actually count as artistic values themselves without thereby becoming, strictly speaking, aesthetic values. If this is, in the end, all that is at issue, a failure to distinguish 'aesthetic' and 'artistic', the debate hitherto conducted fizzles out.

Yet, insofar as autonomism has not provided a positive account or definitions of the types of value at issue, the extent to which the burden of proof can be foisted solely onto the shoulders of its opponents will ultimately depend largely on whether aesthetic value can be positively distinguished from other types of value, including artistic. In this light, it should be noted with caution that the actual relationship posited by autonomism between aesthetic, ethical and artistic value remains opaque. The notions of 'contribute to', 'diminishes', and 'appropriate to' quoted above, shed little light on the positive account of value interaction the autonomist envisions.

Whilst denying the identity of moral features as such with aesthetic features as such, the autonomist, it seems, can accept that the one may impact on the other within the compass of overall artistic value. An unproblematic way in which this might occur would be, for instance, if we cannot stomach any portrayals of Nazism for ethical reasons, we might not be able to pay attention to a film such as Downfall - in which the last days of Hitler are portrayed with some sympathy - in any way that would form the basis for an aesthetic appraisal. In this case, we simply fail to attend to the relevant aesthetic features required to form an aesthetic and overall artistic appraisal. The ethical content of the work affects our ability to be aesthetically engaged with it (see Kieran 2001: 29-30). 
A more difficult case of such interaction for the autonomist, however, would be for example a work in which a naïve or sentimental moral outlook compels an author to write in a glib or artificial way. The impact of the ethical on the aesthetic is, as it were, more direct. Put simply, the worry is that, if the author cannot but help to write in such a way because of the moral content - one might say, very roughly, where the form is determined by the content - or indeed if there are some types of moral content that always contribute to or detract from the aesthetic value of a work, this relationship might be construed in terms of some kind of entailment. And the moralist now appears to have a quick riposte: if certain aspects of ethical value always or necessarily entail certain aspects of aesthetic value, then maintaining the conceptual distinction is little more than a moot point; or at least, the moderate autonomist must offer us stronger reasons for maintaining it, or provide arguments that such relations of apparent entailment never obtain.

To borrow a recent example from Robert Stecker, in order for the novel Green Henry, which deals with a clash of (ethical) values, to achieve its aim, 'the premise must be true, or at least plausible, and it then has to treat this issue insightfully' (Stecker 2005: 147). If it fails in this, the work will have:

'both an ethical defect and an aesthetic defect. The ethical defect is its lack of insight into the positive aspects of traditional systems of value. Its aesthetic defect is its failing to represent a convincing clash of values. The two defects are not identical, but the ethical defect is responsible for the aesthetic defect.'

(Ibid.: 148) [italics mine]

Moreover, the ethical flaw, lack of insight, here is sufficient to produce the aesthetic flaw: failure to represent a convincing clash of values. ${ }^{4}$

The most obvious autonomist response to this, I think, consists simply in emphasising that, even if we grant some kind of entailment between the ethical and the aesthetic, or acknowledge that both kinds of flaws/merits arise from the very same reason or cause, the ethical and aesthetic are still kept resolutely, conceptually distinct by the different descriptions true of each flaw. In the example just presented, for instance, lack of insight or intelligibility, although a sufficient reason for both types of flaw (aesthetic and ethical), is nevertheless, so to say, manifested, and hence identified, differently in each case: 'The ethical defect is its lack of insight into the positive aspects of traditional systems of value. Its aesthetic defect is its failing to represent a convincing clash of values.' As such, it appears that the autonomist can happily allow the interaction, in whatever form, of ethical and aesthetic values within an artwork without collapsing the conceptual distinction between the two. ${ }^{5}$

\section{Kieran's Moderate Moralism}

A direct attempt to undermine such a response, however, has recently been outlined by Matthew Kieran, who advocates a position he labels 'most moderate moralism':

The moral features implicit in and central to the imaginative experience afforded by a work are relevant to a narrative's value as art to the extent that they undermine or promote the intelligibility, with respect to appropriately sensitive

4 On the appeal to sufficient reasons, see Carroll (1998), and Anderson and Dean (1998: 153-6).

5 Perhaps MA could be reinforced here by an account of the supervenience of the aesthetic on the ethical, but any exploration of this must wait for another time. 
audiences, of the characters, events, and states of affairs as represented. (Kieran 2001: 34)

Kieran argues that artworks afford us imaginative experiences that are central to the value of those works. The quality of such experiences, in the case of narrative works of art centrally concerned with moral issues, is partly a function of the intelligibility of the experiences. This intelligibility, in turn, is a function of a combination of the intelligibility of what, following Kieran, we might call the formal, aesthetic elements of artworks - 'coherence and consistency of the imagery' for example - and the intelligibility of what we might call the work's cognitive or moral content - 'how plausible or psychologically probable, informative or explanatory or insightful...' the experience of the work is (Kieran 2001: 35).

In this light, there are certain types of what I shall refer to as 'evaluative critical concepts', which constitute the intelligibility of the imaginative experience a work affords - for example, evaluations of a work as implausible, nuanced, profound, insightful, simplistic, shallow, inane, banal, intelligible, truthful, sentimental, naïve, puerile (Ibid., 35). These properties straddle the boundary, so to speak, between ethical and aesthetic value: it makes no sense to ask further of a work, whether the relevant properties constituting its intelligibility or otherwise are ethical or aesthetic, because it will be, say, shallow, nuanced, or sentimental not just in virtue of its ethical content but in virtue of the way that content is portrayed; via the structural coherence of the narrative, for example.

Kieran's argument seems to trade on the well-worn, yet ineliminably vague idea of the close, perhaps inseparable, intertwining of what is generally called 'form and content', and the implicit equation of aesthetic value or aesthetic properties with the former. ${ }^{6}$ It is crucial to note that many of the central evaluations of art, particularly narrative art, such as those just listed, are properties/evaluations of the way in which something is portrayed, depicted, represented. That is, these properties appear to be essentially ethical or cognitive (or cognitive-ethical) in nature and concern the content of a work, but they also determine, and are determined by the aesthetic properties that constitute the way or manner in which the content is rendered. As such, they have a direct bearing on artistic value.

Now if this is all that is at issue then again, in one sense, the debate fizzles out. For both sides should agree that artistic value is, at least partly, a matter of the way that a work conveys its various cognitive and ethical values, and hence of the way that form and content interact. (Gaut 2006: 122; Lamarque 2006). The critical evaluations at issue are thus undeniably artistic, properties of both form and content, and as such are directly relevant to artistic value. What makes intelligibility and those critical evaluations that embody it relevant to artistic value, is the interconnectedness of form and content that gives rise to both. This seems relatively uncontroversial, and it does not, at least without further argument, make them aesthetic values.

Yet Kieran's claim goes beyond this: the critical values constituting intelligibility are at the same time both ethical and aesthetic values, because they are properties both of intelligibility construed formally (and hence aesthetically) and construed as broadly cognitive-ethical. Hence, the collapse of the treasured conceptual distinction due to the fact that the intelligibility of the imaginative experience is both an ethical and aesthetic value.

6 See Kieran (1996) for a more detailed discussion of the relation between form and content. 
It is worth noting that the argument, as Kieran asserts, does not presuppose cognitivism in the sense that the critical evaluations depend on truth, strictly speaking (Kieran 2001: 35). Nevertheless, it is also worth noting that many of the critical values listed by Kieran as being both ethical and aesthetic in nature, are invoked also by cognitivists as evidence for their thesis that cognitive values in an artwork can sometimes be relevant to its artistic or aesthetic value; and for similar reasons. In particular, cognitivists claim that it is the 'way a work conveys its cognitive merits' that is of artistic relevance. The evaluations are essentially cognitive in nature, even if not dependent upon/related to knowledge and truth, strictly speaking, and they are clearly genuine evaluations of works of art. $^{7}$

I suggest for these reasons that the central claims of both debates can be examined together. It is important to realise firstly, however, that in this debate also, 'artistic' and 'aesthetic' are used more or less interchangeably, this carelessness frequently making it difficult to determine just what the claims of each side actually are and where the dispute really lies, independently of any separate account of just where the overlaps and differences, if any, between aesthetic and artistic value are to be located.

Insofar as the debate concerns merely the relevance of cognitive values to artistic values, there is merely a verbal dispute between the opponents. For if aesthetic values are distinct from others, then there is no reason for an anti-cognitivist to resist the possibility of cognitive values not being relevant just to artistic value, but also to actual artistic values themselves. It is for this reason, however, that the claims of strong anti-cognitivism, outlined below, must be rejected.

The real danger for the anti-cognitivist, and his autonomist counterpart then, lies in the extent to which Kieran's argument can demonstrate that cognitive and ethical values can sometimes be aesthetic values. Ultimately, I argue that it is highly difficult to understand just what this claim amounts to, for the envisaged relationship between ethical, cognitive and aesthetic values depends to a large extent, it seems, on a relationship between form and content, which is itself extremely opaque. More problematically, the form/content distinction cannot be made to do the work required to carry the argument for the cognitivist/moralist.

3. Anti-cognitivism, form and content.

One route initially open to the anti-cognitivist is simply to deny that the relevant critical values are in fact cognitive in any straightforward sense. This seems to be the option favoured by the most prominent 'anti-cognitivists', Lamarque and Olsen, who, limiting their account to literature, and restricting the notions of truth and knowledge to propositional truth and knowledge, then deny that they play any role in the practice of literature as such or have any relevance to the value of literature qua literature. Hence, because cognitive value qua cognitive is a property of truth and knowledge in this narrow sense, insofar as the values at issue are relevant to literary value, they cannot be cognitive, strictly speaking (Lamarque and Olsen 1994).

They argue that literary value consists in the interrelation of a) the design or structure of the work, and b) the thematic development and characterisation of a work's subject matter. Their argument then seems to be that, because it is the way that content is conveyed and developed that is of artistic relevance, the bare cognitive content itself, stripped of the particular form in which it uniquely belongs to some particular artwork, cannot be a genuine artistic value. Either that bare content will be propositional,

7 The clearest outline of the cognitivist debate is given by Gaut (2006), and Lamarque (2006). 
in which case it may be true or false, and will generally be trivial in nature, but will not as such be a genuine artistic value of the particular artwork from which it is derived. Or it may be that the themes relevant to the value of a literary work cannot in fact be reduced to any meaningful proposition(s) - for instance, works might be about 'the path from unacknowledged guilt to perdition' or 'the lack of trustworthiness in humans'(Lamarque 2006: 137). ${ }^{8}$

The cognitivist can here insist that the truth of a work's content may in some cases be relevant to a work's artistic value. The relation may be direct or indirect. In respect of the latter, it can be argued that the critical evaluations at the centre of the dispute whether a work is insightful, banal, or sentimental - are themselves dependent on truth. Shallow, inane or sentimental works, it has been claimed, generally embody false views of reality (Miller 1979: 317). Unfortunately, there is not enough space to explore such views here, but it will serve to note, firstly, that even if we grant them some plausibility in relation to some of the critical evaluations at issue, the sheer variety of these would seem to testify against the general applicability of the claim to them all. More importantly, however, it is simply not clear that any of the values at issue are straightforwardly dependent on truth. Although sentimentality may involve a false conception of its object, falseness is neither necessary nor sufficient for sentimentality; nor need a theme or idea be true to be profound or insightful (Tanner 1977; Lamarque 2006). ${ }^{9}$

Nevertheless, a more direct relation to truth can also be established by the cognitivist in relation to specific artistic genres. In the case of historical fiction, for example, it seems central to the genre to get certain things right, and a failure to do this lessens a work's value as art, at least to some extent; a point that Lamarque (2006: 138) concedes. Or, as Budd argues, 'to appreciate a subtle caricature of X you need to be able to see the distortion in the depicted individual's appearance, which you cannot do without knowledge of the undistorted appearance' (Budd 1995: 71). There are important issues lurking here about the role of intention and genre in deciding on the relevance of truth to artistic value, including an important distinction between whether an artist is trying to get us to adopt some particular conception of reality, or merely to allow us to explore it. Nonetheless, to respond, as Lamarque and Olsen apparently do, that in these cases truthfulness, truthlikeness, accuracy, or sincerity are at issue rather than truth per se, is, I think, inadequate (Lamarque and Olsen 1994: 5-6, Ch. 13; Lamarque 2006).

It is important to realise that a key motivation for the anti-cognitivist is to preserve the autonomous, intrinsic and irreplaceable value of art from the danger of rendering it of merely instrumental value in the service of gaining knowledge. But while there can be no doubt that any plausible view of artistic value must defend these central components of the value of art qua art, in being so narrowly stipulative about what counts as cognitive value, acceptance of the anti-cognitivist position hitherto developed entails paying what to many will appear an unacceptably high price for maintaining the im-

8 Lamarque (2006: 137). Cognitivists at this point generally claim that artworks can provide us with non-propositional knowledge and, furthermore, that this can be a genuine part of a work's artistic value. Examples of such knowledge concern conceptual enrichment, experiential explorations, imagining possibilities and so on. Lamarque and Olsen, however, simply reject the claims of these various conceptions to genuine knowledge status and hold that, if this is all that is meant by cognitivism, then they too are cognitivists.

9 For further discussion of these issues, see Rowe (1997), Gaut (2006) and Lamarque (2006). 
portant autonomy of artistic value. To deny that art qua art can possess cognitive value qua cognitive seems counter-intuitive, and to be connected to an implausibly restrictive notion of artistic (and indeed cognitive) value.

Instead, like her autonomist counterpart, the best route open to the anti-cognitivist is to admit cognitive values qua cognitive to bear on the pluralistic value of art qua art, but not to bear on aesthetic value as such. The anti-cognitivist can then argue that the notion of 'relevant to' is simply too weak to do the work required of it by cognitivists. For the subject matter or bare content - and sometimes the truth - of a work is relevant to its artistic value, in the trivial sense that a work could not be the work it is, and experienced as such, without it. But it is not thereby determinant of a work's value qua art, nor as such an artistic value itself. For, as already stated, artistic value concerns the way in which content is developed so that content stripped bare of all the formal properties that make it an integral part of the work is not only no longer an intrinsically artistic value, but is not because it is simply a different thing altogether.

Thus, the anti-cognitivist should insist that there is no point in thinking of a theme or subject as shallow or inane apart from the particular way in which it is developed, because if it is developed profoundly, then the theme qua artistic/literary theme is not shallow or inane. Stripped of its particularity, thematic content is empty and irrelevant to the value of art qua art, even if further arguments are no doubt required to establish that the way in which thematic content is developed, its artistic significance, is always distinct from its truth.

One important way in which the cognitivist might respond to this is to hold that, even so, the nature of a work might determine the way in which its content is developed. The thought here is that, for example, a shallow, puerile, sentimental or unintelligible idea or subject may inevitably result in a clichéd, clumsy and unintelligible style and structure; these are formal or aesthetic flaws, entailed, as it were, by the (cognitive) nature of the content. In this way, it can be objected, the content of a work may to some extent be determinant of formal, aesthetic value and, the objection continues, if, as seems natural, aesthetic value is an essential ingredient or determiner of artistic value, then surely the cognitive or ethical content of a work can help determine the work's artistic value. ${ }^{10}$

By itself, however, this would not suffice to demonstrate the supposed equivalence of aesthetic and other values - there still seems to remain some sort of conceptual distinction, just as there remains a conceptual distinction between form and content. Moreover, it is highly debatable that such relations really obtain. Even if some of the relevant properties/values can be meaningfully divided as properties of form or content, it is not at all clear that, for example, an idea that is by itself profound or puerile, could not be treated in a shallow or mature way; or an intelligible moral vision be developed in an unintelligible way, through an incoherent narrative structure, for example.

Thus, even if aesthetic can be equated to form and we allow a clear conceptual distinction between form and content, it is far from obvious that the required determination relations actually hold, and even if they did, this would not by itself demonstrate the required conceptual overlap between aesthetic and other values.

More problematically perhaps, it is not obvious that we can divide properties between form and content as straightforwardly as this argument appears to require. Even

10 For a detailed discussion of some of these issues, see Miller (1979: esp. 338); Lamarque and Olsen (1994: 336-7); Budd (1995: 75ff.); Kieran (1996: 343-6); Gaut (2006) and Lamarque (2006). 
if we allow that content can determine form, the converse is also true - what we see, imagine or experience in engaging with an artwork will be determined by how the what is portrayed. Indeed, put in the abstract terms of form and content, this just appears trivially true and suggests that the hazy and unanalysed notion of the interconnectedness of form and content cannot readily support the weight of argument the cognitivist appears to need, for the following reasons.

The notion of form can be cashed out in such a large variety of ways - more or less broadly or narrowly - that it is by no means obvious what they all have in common in virtue of which they are either 'formal' or 'aesthetic.' The vagueness inherent in the notion of form stems from the fact that so-called formal qualities differ across the various types of art and range from base-level perceptual properties to complex structural and organisational principles. Indeed, one attempt to sway the issue in favour of ethicism construes the notion of form so broadly - 'the artistic form of an artwork is the ensemble of choices intended to realise the point(s) or purpose(s) of the artwork' (Carroll 2006: 85) - that it is in danger of becoming empty. Or at least, it is not clear that the same type of appreciation - or the same notion of 'form' - is involved in appraising high-level, cognitively involved, structural features of a work of literature, as in appreciating the soft texture of impressionist brushstrokes, or the heavy alliteration of Old English poetry. As such, not only are the relations between form and content extremely complicated, and the dividing lines between the two often very unclear, it is doubtful whether aesthetic value can straightforwardly be cashed out as formal value, at least without much further argument.

\section{Conclusion}

Many of the critical values, as already noted, are properties of the form/content relation itself and cannot be separated easily into one or the other. For example, a sentimental idea already involves a certain way in which that idea is portrayed - the harsh death of a little girl called Nell is not in itself sentimental; it is how the death is treated and conceived that makes it sentimental. Indeed, it makes no sense to think of Nell's death qua Nell's death apart from the way it is treated. To call a work sentimental, therefore, involves an evaluation of its formal (aesthetic) and content (cognitive-ethical) elements at one and the same time, as Kieran's argument recognises, and this is indeed an essential part of the work's artistic value. Does it then follow that the relevant critical evaluations are both simultaneously cognitive-ethical and aesthetic?

The answer to this question will clearly be 'yes', if this simply means that such artistic appraisals 'encompass', so to speak, both ethical-cognitive and aesthetic evaluations. This, after all, is just what the pluralism of artistic value allows. But the answer must be 'no' if the implication is that the artistic (dis)values of insight or sentimentality are held to be somehow conceptually irreducible to their component parts. Or to put it another way, even if the artistic value of the 'intelligibility of the imaginative experience' is held to comprise both aesthetic and ethical-cognitive values, these remain conceptually distinct and can in principle - even if this is not always straightforward in practice - be captured under different descriptions, just as the (aesthetic) intelligibility of, say, formal elements in a work is different from the (ethical) intelligibility of a work's moral vision, albeit the same word, 'intelligibility', is used in each case.

To see this more clearly, recall that artistic value is, partly, a function of the 'way in which content is conveyed or treated'. Note the crucial ambiguity inherent in this phrase, which could refer to the cognitive, ethical or aesthetic way in which the con- 
tent is conveyed. For example, a novel might convey its thematic content with ethical insight, with cognitive coherence, or with aesthetic subtlety. And this content might in turn be aesthetic, ethical or cognitive in nature. So, if a work demonstrates ethical insight, this will of course be partly due to the formal or aesthetic characteristics constituting the way that 'content' is achieved, but that does not entail that the insight at issue is both aesthetic and ethical; indeed, there may be aesthetic insight - if that notion is meaningful - involved in or even responsible for the lack of ethical insight, for example.

The fundamental question, therefore, seems to be what makes a particular use of critical evaluative terms, or the particular elements they pick out, aesthetic, ethical or cognitive. Or, to put it another way, we need to substitute the idea of values as fixed properties with the notion of evaluations and their function. We need to know what counts as expressing an aesthetic interest, having an aesthetic experience, making an aesthetic judgement vis-à-vis having a cognitive or ethical interest or experience or judgement. Only then can we decide whether it makes sense to think that the critical evaluations at issue can function simultaneously as aesthetic and non-aesthetic evaluations. To offer such an account is a sine qua non of any resolution of these issues, and hence can no longer be shirked by either side in each debate.

\section{References}

Anderson, J. \& J. Dean. 1998. 'Moderate Autonomism', British Journal of Aesthetics $38,150-166$.

Carroll, N. 2006. 'Ethics and Aesthetics: Replies to Dickie, Stecker, and Livingston', British Journal of Aesthetics 46, 82-95.

- 2000. 'Art and Ethical Criticism: An Overview of Recent Directions of Research', Ethics 110, 350-387.

- 1998. 'Moderate Moralism versus Moderate Autonomism', British Journal of Aesthetics 38, 419-424.

- 1996. 'Moderate Moralism', British Journal of Aesthetics 36, 223-38, reprinted in Carroll, N. 2001. Beyond Aesthetics: Philosophical Essays, 293-306. Cambridge: Cambridge University Press.

Gaut, B. 2006. 'Art and Cognition', in M. Kieran (Ed.), Contemporary Debates in Aesthetics and the Philosophy of Art, 115-26. Blackwell: Oxford.

- 1998. 'The Ethical Criticism of Art', in J. Levinson (Ed.), Aesthetics and Ethics, 182-203. Cambridge: Cambridge University Press.

Kieran, M. 2002. 'Forbidden Knowledge: The Challenge of Immoralism', in J. Bermudez \& S. Gardner (Eds.), Art and Morality, 56 - 73. London: Routledge.

- 2001. 'In Defence of the Ethical Evaluation of Narrative Art', British Journal of Aesthetics, 41, 26-38.

- 1996. 'Art, Imagination, and the Cultivation of Morals', Journal of Aesthetics and Art Criticism 54(4), 337-351.

Lamarque, P. 2006. 'Cognitive Values in the Arts: Marking the Boundaries', in M. Kieran (ed.) Contemporary Debates in Aesthetics and the Philosophy of Art, 127 39. Blackwell: Oxford. 
Lamarque, P. \& S. Haugom Olsen. 1994. Truth, Fiction and Literature. Oxford: Clarendon Press.

Miller, R. 1979. 'Truth in Beauty', American Philosophical Quarterly 16(4), 317-325.

Rowe, M. 1997. 'Lamarque and Olsen on Literature and Truth', Philosophical Quarterly 47, 322-41.

Tanner, M. 1977. 'Sentimentality', Proceedings of the Aristotelian Society 77, 127-47. 